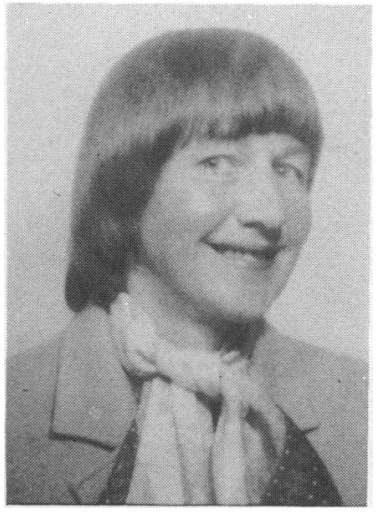

K. Elizabeth Dowey

\title{
A SURVEY OF ROLLER DISCOTHEQUE INJURIES
}

\author{
K. Elizabeth DOWEY, MRCP (UK)
}

Consultant Physician, Accident and Emergency Department, Belfast City Hospital, BELFAST

Dancing on roller skates at discothecques has become very popular among the youth in the last number of years. During 1980 a number of these roller discotheques were opened in Belfast and it soon became apparent that significant numbers of young people were attending the Accident and Emergency Departments of hospitals in the city with injuries received while participating in this leisure activity.

As these injuries were becoming more frequent, it was decided to analyse those presenting at the Accident and Emergency Department of the Belfast City Hospital for the period September 1980-September 1981.

\section{CLINICAL DATA}

In all 158 patients were assessed. The patients numbered 107 females and 51 males. The female:male ratio was 2:1. The ages ranged from $5-43$ years, the average age being 16.5 years. A peak is evident in the 12-16 age group (Fig. 1). There were only six patients over 24 years. The oldest, a 43-year old was skating with her 12-year old son - she sustained a Type B fracture of the ankle and he sustained a greenstick fracture of the left wrist.

Ten patients required admission to hospital. Five were admitted to the Observation Ward following head injuries and were discharged the following day, and five were admitted to the Orthopaedic Unit for reduction and immobilisation of fractures for stays ranging from 2-16 days.

\section{RESULTS}

The total number of injuries sustained was 167 . Of these, 149 patients had one injury while the remainder had more than one. The anatomical distribution of the injuries as a whole is shown in Figure 2.

Isolated soft-tissue injury occurred in 105 patients
(62.8\%). The major type of soft-tissue injury was blunt injury to the limbs. The distribution is shown in Table $\mathrm{I}$.

\section{TABLE I}

Types of isolated soft-tissue injury

\begin{tabular}{|c|c|}
\hline Blunt injury to limbs & 68 \\
\hline Head injuries without fractures & 13 \\
\hline Strains of back and neck & 9 \\
\hline Wounds of extremities & 7 \\
\hline Scalp and facial lacerations & 4 \\
\hline Miscellaneous & 4 \\
\hline
\end{tabular}

In the group as a whole there were 62 fractures $(37.1 \%)$. The majority of these involved the forearm and wrist. The distribution of the sites of fracture is shown in Table II.

\section{TABLE II}

Sites of fracture

\begin{tabular}{|c|c|}
\hline Forearm and wrist & 37 \\
\hline Ankle & 8 \\
\hline Hand & 4 \\
\hline Tibia & 3 \\
\hline Foot & 3 \\
\hline Elbow & 3 \\
\hline Shoulder & 2 \\
\hline Back & 2 \\
\hline
\end{tabular}




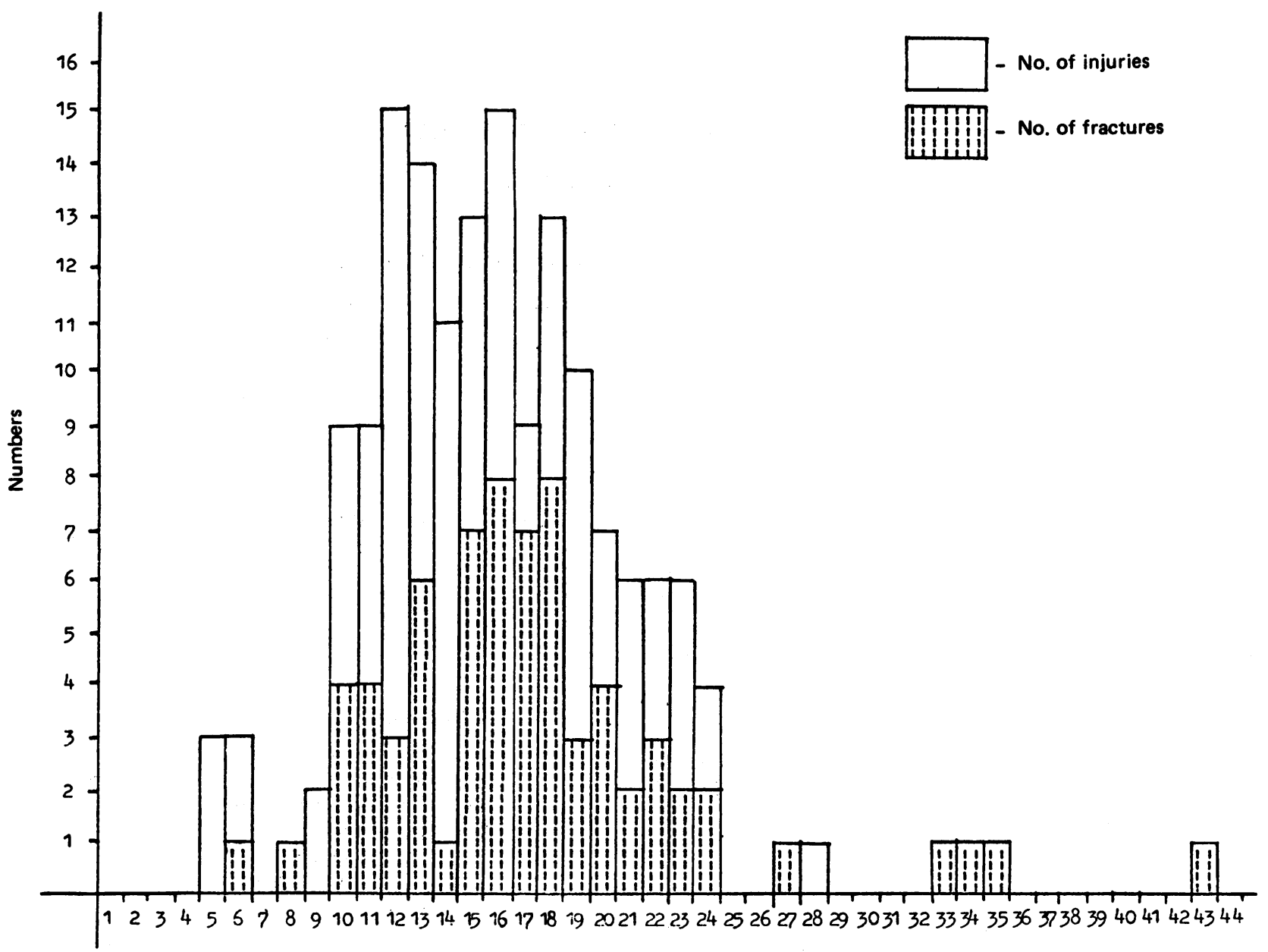

Age in years

Fig. 1. Histogram: distribution of fractures and other injuries

Most of the 37 wrist and forearm fractures were not serious. However there were 3 Salter Type II epiphyseal injuries of the distal radius, 8 displaced fractures of the distal ends of the radius and ulna, 2 fractures of the waist of the scaphoid and one displaced lower radial epiphysis. Of the 8 fractures. in the region of the ankle there were 5 fractures of the lateral malleolus (Type B), 1 Salter Type II epiphyseal injury of the distal tibia, and 2 spiral fractures of the lower third tibia.

Five patients were admitted to the Orthopaedic Unit for reduction under general anaesthetic. There were no compound fractures. Forty-three cases had application of plaster of Paris casts, and reduction (if necessary) under intravenous regional analgesia, carried out in the Accident and Emergency Department. These patients were kept under review at the Department for an average period of 4-5 weeks.

\section{DISCUSSION}

Roller discotheque dancing has a wide appeal as can be seen from the age range. In spite of the fact that females were in the majority by $2: 1$ it was evident that the males sustained the more severe injuries. Seven males were admitted to hospital while only three females required admission. Five of the ankle fractures were in males and also five of the significantly displaced wrist fractures. These findings may be due to the fact that boys tend to travel at greater speeds on the roller skates and perform more daring twisting movements.

It is apparent that the injuries sustained are comparable but less severe than those associated with skateboarding, which is a similar pastime. In this study it was noted that the incidence of fractures was $37.1 \%$, the majority of these involving the forearm and wrist. Similar findings related to skateboarding were reported 


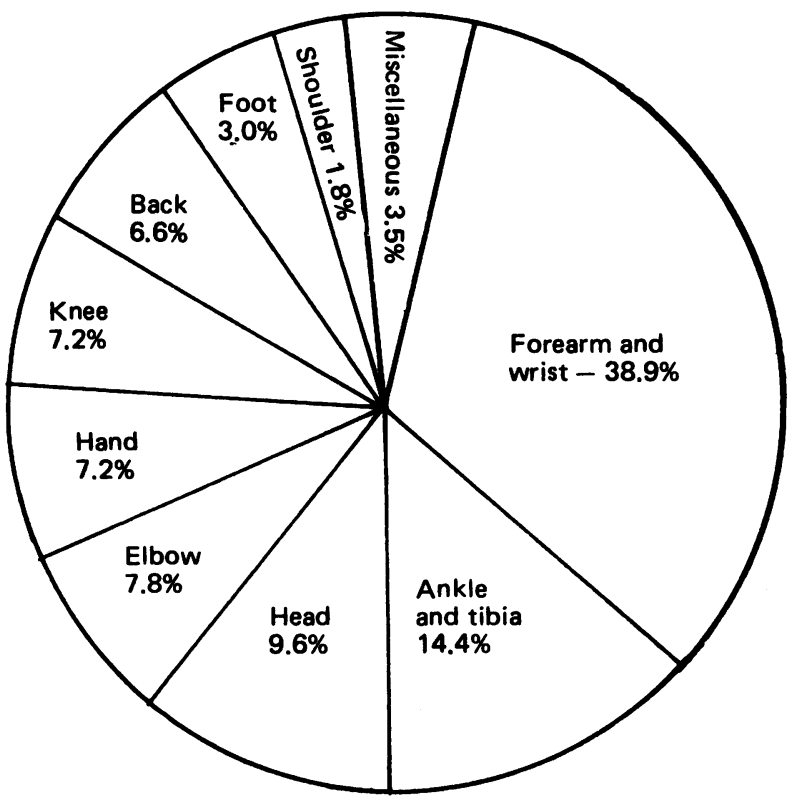

Fig. 2. Anatomical distribution of injuries.

both in the British Isles by Illingworth et al (1978) and in the United States by Alienza and Dia (1976), Maddox (1978), and Hawkins et al (1981).

Alienza and Dia (1976) also reported more serious injuries such as rupture of the spleen, retroperitoneal haemorrhage and serious renal damage.

In Illingworth's series $4 \%$ of the patients required admission to hospital. This is similar to this study (6.3\%) but both are lower than the figure of $18.3 \%$ recorded by Hawkins et al (1981).

To date no deaths from roller discotheque skating have been reported in Great Britain. However the Royal Society for the Prevention of Accidents (1978) has reported three deaths in Great Britain from skateboarding between December 1977 and March 1978, while Rutherford et al (1977) reported in the United States at least twenty-five deaths from skateboarding.

The increased risk with skateboards is possibly due to the greater speeds attained and also to the fact that many young people skateboard on the public highways rather than on purpose designed rinks.

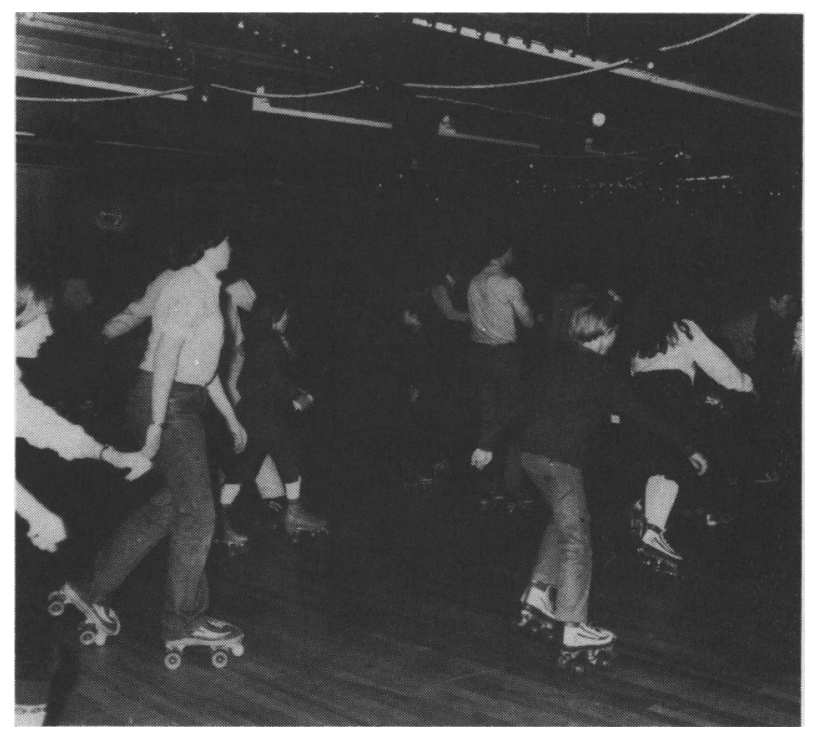

Roller Discotheque

Nevertheless all forms of roller skating including roller discotheque dancing are potentially dangerous sports and it is evident that the number of injuries is rising. Thus, with the increasing popularity of this leisure activity a significant number of days are being lost from school and work.

This study suggests that all types of roller skating injuries could be reduced if skating was restricted to areas specifically intended for such purposes. These would require to conform to a set of safety standards and design. Included in this should be pre-use equipment checks, the use of protective gear, and standardisation of skating surfaces. Instruction should be provided on skating techniques involving falling, turning and stopping. Dance floors should not become overcrowded where injuries occur from people crashing into one another, dancing should be segregated from other skating events such as attempts upon speed records, and a separate area should be designated for beginners.

Finally more research on roller skate design and skating related injuries would be needed.

While this paper has been in press, a further article on this subject has been published, on a different series of patients from another Belfast Hospital by Wilkinson, showing similar results.

\section{REFERENCES}

Alienza F. and Sia C., 1976 "The hazards of skateboard riding". Paediatrics 57: 793. 
Hawkins, W. H. and Lyne, E. D., 1981 "Skateboarding fractures". The American Journal of Sports Medicine 9 (2): 99-102.

Illingworth, C. M., Jay, A., Noble, D. and Collick, M., 1978 “225 skateboard injuries in children”. Clinical Paediatrics 17 (10): $781-789$.

Maddox, D., 1978 "Skateboarding: the spill and skill sport". The Physician and Sportsmedicine 6: 108-114.

Royal Society for the Prevention of Accidents, 1978.

Rutherford, G. W., Friedman, J. I., Beale, S. P. and Brown, V. R., US Consumer Product Safety Commission, 1977.

Wilkinson, A. J., 1982 “Injuries incurred at 'roller discos' ". British Medical Journal 284: 1163.

\section{BOOK REVIEWS}

"Women and Sport" and "The Female Athlete" are two books in a series on Medicine and Sport which are edited by E. Jokl and M. Hebbelinck, the two books consist of a series of selected papers from the International Congress of Women in Sport which was held in Rome in July 1980.

Title: $\quad$ WOMEN AND SPORT: An historical, biological, physiological and sportsmedical approach

Editors: $\quad$ J. Borms, M. Hebbelinck and A. Venerando, 1981

Publisher: $\quad$ Karger, Basel.

Price \$74.25 232 pages, 56 figures, hard cover

"Women and Sport" consists of the historical aspects of the involvement of women in sport in various countries, it also contains a section on the physiology and biochemistry of exercise in women, there are only five papers associated with sports medicine problems in women.

Title: THE FEMALE ATHLETE: A socio-psychological and kinanthropometric approach

Editors: $\quad$ J. Borms, M. Hebbelinck and A. Venerando, 1981

Publisher: $\quad$ Karger, Basel.

Price \$74.25 218 pages, 44 figures, hard cover

"The Female Athlete" consists of a series of papers associated with the sociological aspects of women in sport and sports psychology. The last section is a series of papers on body composition and somatotypes of various women athletes.

These books contain useful information for anyone who is involved in training or looking after women athletes.

Moira O'Brien 